\title{
Bioelectricity production of PMFC using Lobelia Queen Cardinalis in individual and shared soil configurations
}

\author{
Grégory Bataillou*, Naoufel Haddour, and Christian Vollaire \\ Laboratoire Ampère (CNRS), Université Claude Bernard Lyon 1, Insa Lyon, Ecole Centrale de Lyon, 36 avenue Guy de Collongue - \\ 69134 Ecully
}

\begin{abstract}
Plant Microbial Fuel Cell (PMFC) creates electricity from oxidation of root exudates by microbia anaerobic digestion, and reduction of dioxygen to water. In this study, Lobelia Queen Cardinalis was used as a plant model to investigate the impact of ionic connection between stacked Plant microbial fuel cell (shared soil). $10 \mathrm{~mm}$ thickness carbon felt woven with stainless steel wire was used for both anode and cathode, and soil was a mix of potting soil and ground from pond banks (30\\%-70\\% weight, respectively). Independent performances did not show any difference between individual and shared soil PMFCs. Stacking independent PMFC in series sums both open circuit potential (OCP) and internal resistance, while stacking in parallel sums current, keeping open circuit potential to the mean of the OCPs. Although series stacking seems to output best performances, this configuration may cause voltage reversal in one PMFC when current is strong, leading to biofilm damage, so stacking in parallel is recommended.
\end{abstract}

\section{Introduction}

Plant Microbial Fuel cells are promising alternatives for renewable energy harvesting systems. These electrochemical systems use plants and exoelectrogenic bacteria to convert the carbon stored in the soil into electrical energy [1]. Thanks to photosynthesis, plants are able to transform carbon dioxide $\mathrm{CO}_{2}$ into sugars such as acetate or glucose. Surplus of produced sugars are excreted by the roots, as root exudations and are therefore translocated into the soil [2]. These organic molecules are used as renewable resource in PMFC for electrical energy production. A typical PMFC comprises an anode installed deep in the soil (anaerobic region), a cathode placed on the ground surface (aerobic environment), separated by the soil which acts as a membrane, and connected by an external electrical circuit (fig.1). At the anode, anaerobic bacteria naturally grow to form a biofilm, which oxidizes organic rhizodeposits, resulting in a release of electrons and protons. Electrons transmitted to the anode are carried away by the external circuit, and protons are transferred across the cathode via soil. This flow of charges generates electrical energy. At the cathode, a reduction reaction occurs, where electrons, protons and oxygen react to form water. Dioxygen is often used as the electron acceptor, because it is abundant and has a quite good electronegativity [3]. Theoretically, the PMFC generates a maximum electrical power output of $3.2 \mathrm{~W} / \mathrm{m}^{2}$ (280 $\mathrm{MWh} /$ ha year) [4].Although this power density is lower than that of photovoltaic panels, PMFCs can generate continuous energy without need for energy storage systems, without competition for food and can be operated at any location. However, several factors limit the implementation of larger scale PMFC for real application.

Main disadvantages of PMFC are relatively low power densities production and loss of performances in scaled-up systems. The connection of multiple PMFCs in parallel and in series, is a way to boost output voltage and current of larger scale system. This stacking approach has been already described for Microbial Fuel Cells (MFCs) for wastewater treatment and sediment MFCs [5] . Only one recent study of Pamintuan's group, described the stacking behaviour of individual PMFCs [6]. This study demonstrates that a combination of series and parallel connection between cells might be the best choice to extract more performances in individual PMFCs. However, the individual configuration of PMFCs used in this study (PMFCs do not share the same soil), is not suitable for large scale application where PMFCs share the same soil. Indeed, two main configurations could be used to study PMFCs : (1) individual PMFCs planted in single pots without any ionic connection between them [7], [8] [9] ; (2) soil shared PMFCs that are directly planted in the same ground maintaining ionic connection between them, [1], [10]. The soil shared configuration is more appropriate for real application, for example, to combine agriculture and electricity production. In this configuration, ionic connection between PMFCs could greatly change stacking behaviour of connected cells as previously reported for MFCs[11].

Herein, we describe the study of the stacking behaviour of PFMCs in both individual and shared soil configurations. The primary goal of this work was the investigation of the

\footnotetext{
* Corresponding author: gregory.bataillou@ec-lyon.fr
} 
impact of shared soil on PMFC performances. Then, performances and behaviour of stacked PMFCs in shared soil and in individual soil were compared. To the best of our knowledge, this study was never reported.

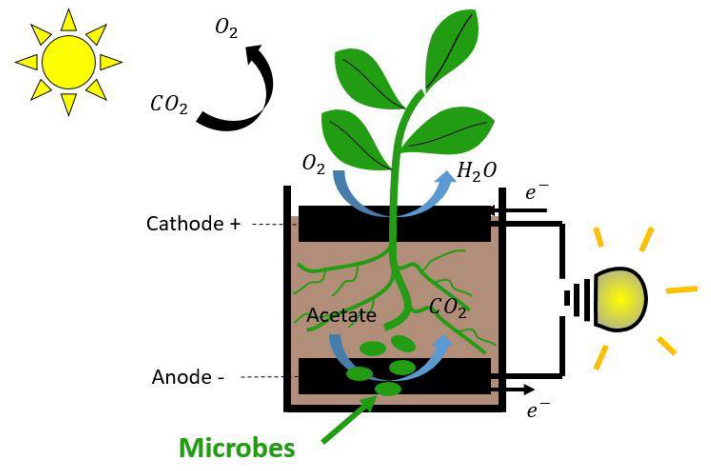

Fig. 1. Example of Plant microbial fuel cell system

\section{Materials and methods}

\subsection{Experimental setup}

Ten single-chamber PMFCs were built with $3.5 \mathrm{~L}$ plastic conical pot as base container $(17.5 \mathrm{~cm}$ deep). For 6 of them, pots were connected together by 3 . The remaining 4 pots were independents (fig. 2) There were no holes at the bottom of the pots, in order to keep the soil constantly immersed. This prevented dioxygen to diffuse to the anode and kept ionic conductivity between electrodes. Electrodes were made with $10 \mathrm{~mm}$ carbon felt cut in circle (Graphitech, FR). Anodes had a diameter of $13.2 \mathrm{~cm} \pm$ $0.2 \mathrm{~cm}$ (surface area $0.014 \mathrm{~m}^{2}$ ) and cathodes had a diameter of $17.5 \mathrm{~cm} \pm 0.5 \mathrm{~cm}$, with a $5 \mathrm{~cm}$ hole at the middle in order to let the plant grow (surface area $0.021 \mathrm{~m}^{2}$ ). Distance between anode and cathode were chosen to be $7.5 \pm 0.5 \mathrm{~cm}$. The choice of this distance originates from preliminary studies: pots with interelectrode distances below $7 \mathrm{~cm}$ did not start well, certainly because of dioxygen diffusion (no membranes were used). Besides, Takanezawa et al. [12] found out that, within the same configuration, $5 \mathrm{~cm}$ distance gave better performances than $2 \mathrm{~cm}$. Although it depends on the ionic conductivity, this interelectrode distance must be high. Collectors were stainless steel wire AISI316, $0.25 \mathrm{~mm}$ thick (GoodFellow) woven inside the electrodes, and attached to copper wire with dominoes. As good contacts, flatness and inter-electrodes distance were not easy to reproduce, contact resistance was considered as acceptable if it was under $50 \Omega$ (using ohmmeter between carbon and the end of the wire. Inoculation was made with acetate just once at the begining (Acetate sodium, $1 g . L^{-1}$ ), and already living organisms in ground/potting soil. $\mathrm{pH}$ was not buffered, as the commonly used phosphate buffer solution (PBS) seems to have an uncleared impact on PMFC [13]. $\mathrm{pH}$ was measured at the end of the experiment. Plants used were Lobelia Queen Cardinalis, and were bought in a garden center already $5 \mathrm{~cm}$ tall with 5 to 10 leaves. All pots were installed in a closed rack with LED attached above each floor. Temperature was left in the range of 15 to $25^{\circ} \mathrm{C}$. Plants were lighted with $43 \mathrm{~W}$ LED, $12 h . d a y^{-1}$. As already stated above, pots were constantly immersed to respect water-logged conditions, as it is a quite important parameter [14]. To prevent chemical imbalance inside the shelf (especially abundance of $\mathrm{CO}_{2}$ ), $5 \mathrm{~V}$ fans were used to create a slight overpressure inside the shelf and aerate the place. All results were made in triplicate to avoid statistical errors and misinterpretation.

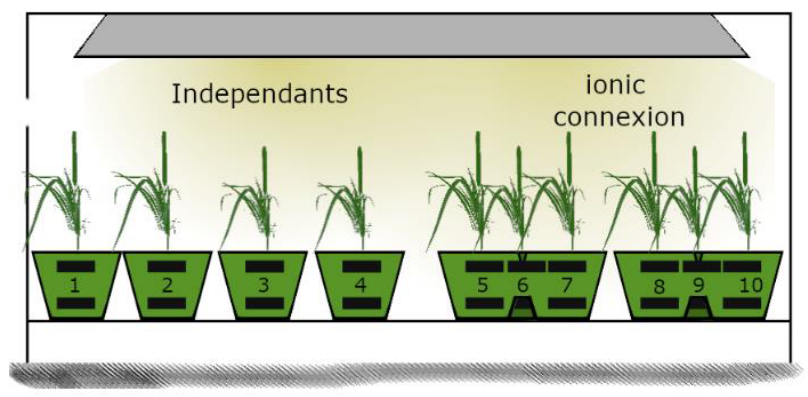

Fig. 2. Experiment plan

\subsection{Potential logging}

Starting from day 0 , current through $680 \Omega$ external charge and open circuit potential between anode and cathode were measured every other day with a voltmeter. Once current measurements were made, these ones were disconnected from the PMFCs, and the measurements of open circuit potential was made after waiting 15 minutes at least. Electrodes potential vs $\mathrm{Ag} / \mathrm{AgCl}$ were also logged, at open circuit and with the charge connected.

\subsection{Internal resistance}

Internal resistance $\left(R_{\text {internal }}\right)$ of each MFC was estimated with the two used functioning points, open circuit and $680 \Omega$ external charge :

$$
R_{\text {internal }}=R_{\text {external }} * \frac{O C P-V_{\text {external }}}{V_{\text {external }}}
$$

where $R_{\text {external }}$ is the external resistance connected to $\operatorname{PMFC}(680 \Omega), O C P$ is the open circuit potential, and $V_{\text {external }}$ is the voltage across external resistance.

\subsection{Electrode contribution to internal resistance}

As mentioned above, internal resistance is limiting the maximum extracted power from the Plant MFC. this 
internal resistance implies voltage loss, and depends on electrolyte conductivity and resistance across electrodes (due to mass transfer, and reaction kinetics) [15]. To know which electrode contributed more to the internal resistance of the PMFC, a linear model was defined, where internal resistance can be separated into 2 contributors: anode and cathode (Fig.3).

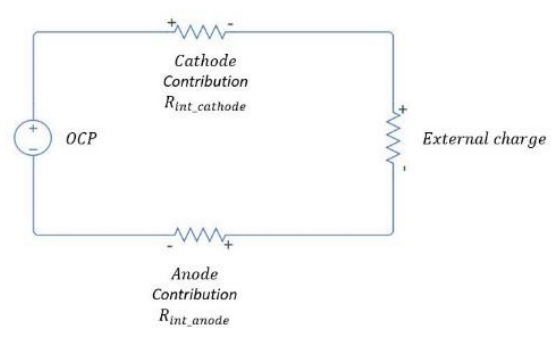

Fig. 3. Electrical model of PMFC with separated electrode contribution

It is then possible to separate the electrode contribution to internal resistance $R_{\text {int }}$ electrode as following :

$$
R_{\text {int }} \text { electrode }=\frac{V_{\text {electrode }}}{i}=R_{\text {external }} * \frac{V_{\text {electrode }}}{V_{\text {external }}}
$$

where $i$ is the current flowing through the external charge, $R_{\text {external }}$ is the external charge used, $V_{\text {external }}$ is the voltage across the external charge, and

$$
V_{\text {electrode }}=\left|E_{\text {electrode }}^{\text {charge }}-E_{\text {electrode }}^{\text {OCP }}\right|
$$

Where $E_{\text {electrode }}^{\text {charge }}$ is the potential of the electrode potential (compared to $\mathrm{Ag} / \mathrm{AgCl}$ reference electrode) when external charge is connected, and $E_{\text {electrode }}^{O C P}$ and is the same potential on open circuit mode. Then, internal resistance is the sum of the two contributions :

$$
R_{\text {internal }}=R_{\text {int }_{\text {cathode }}}+R_{\text {int }_{\text {anode }}}
$$

It has to be stated that the result is mainly qualitative, and should be used as a comparison method only. Indeed, calculation of internal resistance with 2 points can lead to quantitative errors, especially when 1 point is outside the linear domain of the V-I PMFC curve (in this case the Open circuit potential point). Besides, this model does not take into account electrolyte and membrane (if exists) resistance, since they are included in $R_{\text {int }}$ anode and $R_{\text {int }}$ cathode . Therefore, any difference between $R_{\text {int }}$ anode and $R_{\text {int }}$ cathode will imply inequalities between electrode resistance, no matter the value of electrolyte resistance, considered to be distributed evenly. Not taking this value into consideration still allows to investigate which electrode is contributing more to the internal resistance, and then is limiting the current density.

\subsection{Stacking}

During measurements, 3 individual soil pots were stacked together, and 3 sharing soil pots as well. Stacking of PMFCs was either in series or in parallels (fig.4). Internal resistance estimations were made, in order to compare them to single pots average.

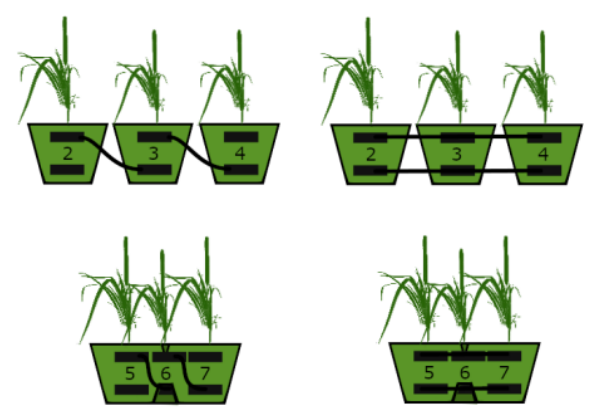

Fig. 4. Stacking combinations

Open circuit potential and current through external resistance were also logged for stacked PMFC regularly. PMFC were connected together, and measurements were made when the system was stable. This allowed to estimate global internal resistance of a stacked PMFC system. However, as different plants are used when comparing shared soil and individual soil stacking, there is a bias. Indeed, every PMFC do not have the same performances at the same time, and results of stacking will be dependent on single PMFC performances at that specific time. To avoid this bias, normalization was made on open circuit potential and internal resistance to respectively average open circuit potential and average internal resistance of used PMFC.

\section{Results and discussions}

\subsection{Biofilm formation}

All PMFC started 7 days after their implementation. These results indicate that living potting soil and ground as matrix substrate already contain exoelectrogen microorganisms, and addition of acetate made them competitive at the electrode surface. There were no differences between pots ionically connected and individual pots in terms of startup duration. These results ensure that ionic connection between PMFCs does not affect biofilm formation. Moreover, the anode potential $\log$ allowed to understand that the biofilm was stable when potential at open circuit reached about $-400 \mathrm{mV}$ vs $\mathrm{Ag} /$ $\mathrm{AgCl}$. Interestingly, when potential of anode was reached, open circuit voltage and current through external charge didn't reach the steady state yet, and a second growth phase was observed (fig. 5.a). Cathode contribution to resistance was still huge compared to the anode, but decreased during this second phase, until stability was reached (fig. 5.b). This behaviour might be explained by the development of 
a aerobic biofilm on the cathode with slower kinetic than that of anodic biofilm [16] [3]. However, further investigations are required to determine the structure of this cathodic biofilm and its growth kinetics.

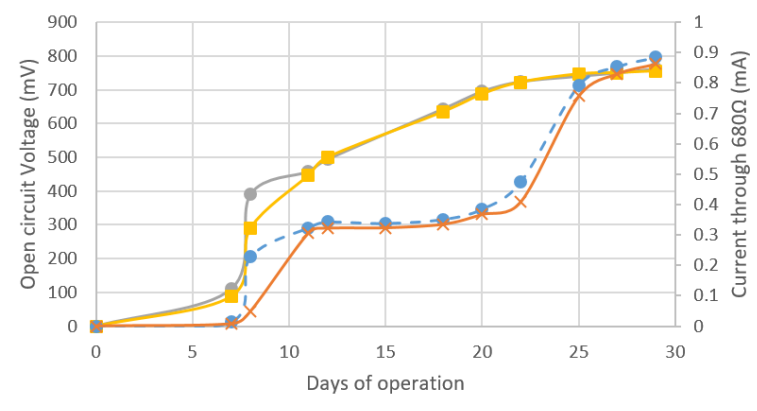

a. Open circuit potential and current through $680 \Omega$

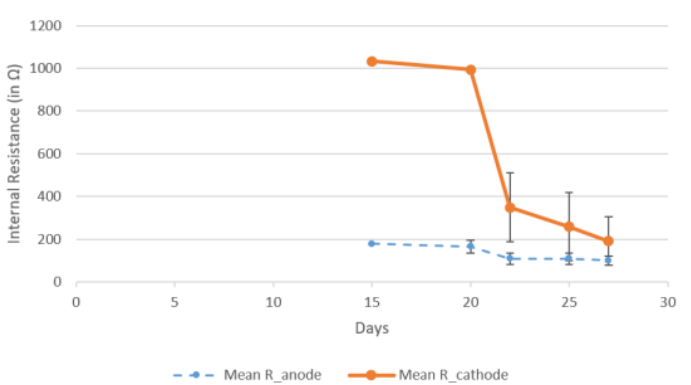

b. Evolution of each electrode contribution to internal resistance

Fig. 5. PMFC startup

\subsection{Study of individual and shared soil configurations}

\subsubsection{Steady state}

On steady state, open circuit potential and current was found to be identical between shared soil plant and unique plant. The maximum current obtained through $680 \Omega$ external charge was $0.92 \mathrm{~mA}$, and was reached by both individual (1 and 2) and soil shared (6,8 and 10) PMFCs, showing no significant difference between the two configurations. Interestingly, it was observed that breakdown of one ionically connected plant did not interfere with other PMFC of the same ground (fig.6).

\subsubsection{Stacking}

Stacking microbial fuel cell was studied and compared with the average of related plants performances. Stacking in series with shared soil PMFC is certainly the worst configuration. Open circuit potential is slightly increased, but not as much as internal resistance, which renders the performances of the stacked PMFC system even worse than one single PMFC. When stacking in series with individual pots, open circuit potential was found to be the sum of all single open circuit potential (fig. 7.a.). However, two major concerns make that configuration not advisable.
First, internal resistance is multiplied by more than 3 (fig.7.b.) which limits considerably the power output. Second, voltage reversal was observed on strong functioning current, and biofilm damage due to this polarization can be irreversible. Voltage reversal has been found when using an external charge of $50 \Omega$ on individual soil plant in series. The PMFC on which it appeared was the weakest one in terms of individual performances.

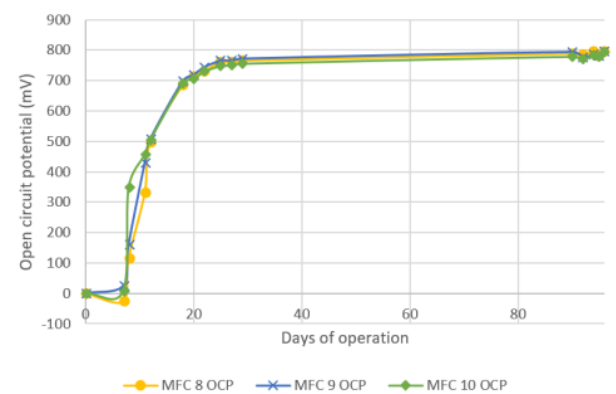

a. Open circuit potential

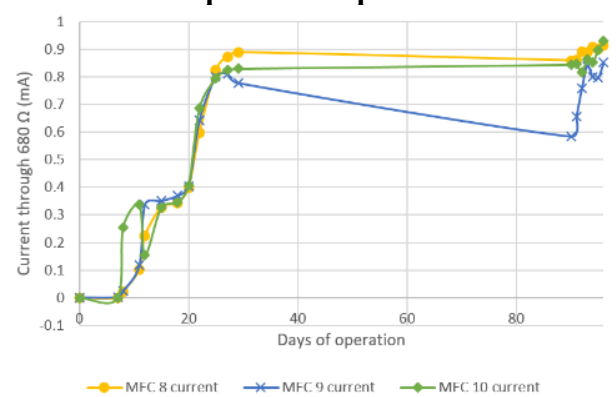

b. current through $680 \Omega$

Fig. 6. PMFC log in shared soil

Stacking PMFC in parallel might be the right choice, regardless of the ground connection. Open circuit potential is the mean of the three single open circuit voltage, and internal resistance is almost divided by three, which allows to drag more power.

\subsubsection{Stacking when breakdown of one PMFC}

One single PMFC voltage and current dropped from day 87 of experiment. This allowed to look at the evolution of stacking performances when one plant microbial fuel cell broke down. It appears that the stacked PMFC system reacts as previously described: the multiplication factor was not changed according to the chosen configuration. The sum of internal resistance in series show that a breakdown of one PMFC can drastically limit the current flow.

\subsubsection{Perspectives}

Cathode contribution to internal resistance was higher than the anode one, even if cathode area was larger and reduction was catalysed after 3 weeks. This result implies that, although this PMFC configuration is mainly used and other configurations have been tested [17] [18], research on low-cost and easy-to-build configuration still needs to 
be done to reduce the cathode limitation. Biocathode is a really interesting way to catalyse dioxygen reaction [3]. Besides, internal resistance can be drastically reduced with higher ionic conductivity [19]. Studying PMFC stacking at different conductivities could lead to different electrons transfer limitations, and might lead to new conclusions.

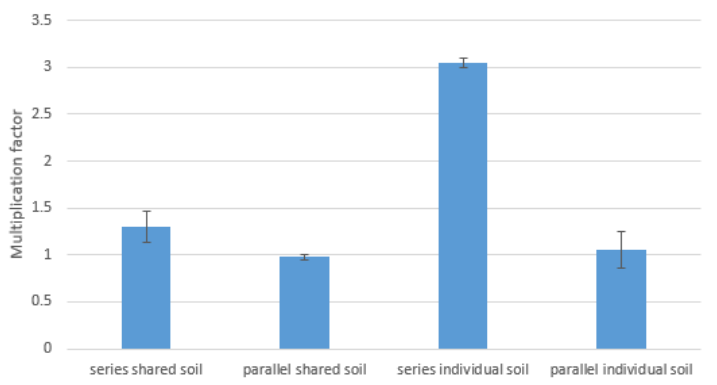

a. Open circuit potential multiplication factor

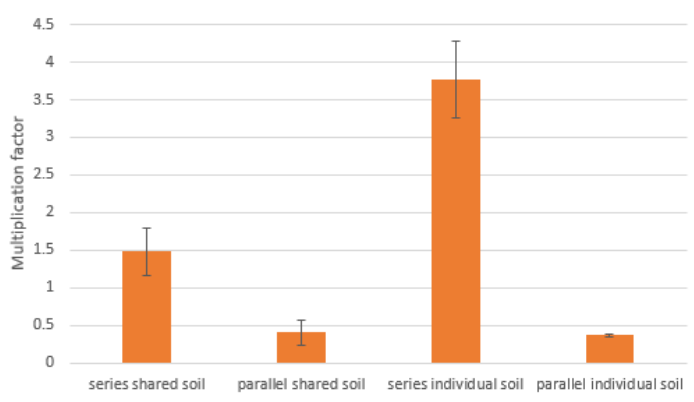

b. Internal resistance multiplication factor

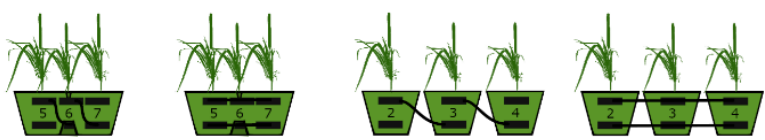

Fig. 7. PMFC log in shared soil

\section{Conclusion}

Lobelia Queen Cardinalis was used in plant microbial fuel cell systems. PMFC with another broken PMFC in the same soil is not affected by this breakdown. Cathode limitation was shown at the begining, but supposed biofilm formation at the cathode increased this one's performance to the same level as anode, when comparing contribution to internal resistance. When stacking multiple PMFC in series, both internal resistance and open circuit potential increase. In case of ionic connection, strong interferences are making the stacking even less efficient than only one PMFC. Parallel connection should be preferred in both individual and shared soil to avoid voltage reversal in one PMFC.

This work was financially supported by the "Hubert Curien Program" through the PHC MAGHREB Project number 19MAG23/41382WC.

\section{References}

[1] N. Kaku, N. Yonezawa, Y. Kodama, et K. Watanabe, «Plant/microbe cooperation for electricity generation in a rice paddy field $», A p p l$ Microbiol Biotechnol, vol. 79, $\mathrm{n}^{\circ}$ 1, p. 43-49, mai 2008, doi: 10.1007/s00253-008-1410-9.

[2] T. S. Walker, H. P. Bais, E. Grotewold, et J. M. Vivanco, «Root Exudation and Rhizosphere Biology », Plant Physiology, vol. 132, $\mathrm{n}^{\mathrm{o}}$ 1, p. 44-51, mai 2003, doi: 10.1104/pp.102.019661.

[3] K. Wetser, E. Sudirjo, C. J. N. Buisman, et D. P. B. T. B. Strik, «Electricity generation by a plant microbial fuel cell with an integrated oxygen reducing biocathode », Applied Energy, vol. 137, p. 151-157, janv. 2015, doi: 10.1016/j.apenergy.2014.10.006.

[4] D. P. B. T. B. Strik, R. A. Timmers, M. Helder, K. J. J. Steinbusch, H. V. M. Hamelers, et C. J. N. Buisman, «Microbial solar cells: applying photosynthetic and electrochemically active organisms », Trends in Biotechnology, vol. 29, $\mathrm{n}^{\circ} 1$, p. 41-49, janv. 2011, doi: 10.1016/j.tibtech.2010.10.001.

[5] W. H. Tan et al., «Microbial Fuel Cell Technology-A Critical Review on Scale-Up Issues », Processes, vol. 9, n 6, Art. n ${ }^{\circ}$ 6, juin 2021, doi: 10.3390/pr9060985.

[6] K. R. S. Pamintuan, J. A. A. Clomera, K. V. Garcia, G. R. Ravara, et E. J. G. Salamat, «Stacking of aquatic plant-microbial fuel cells growing water spinach (Ipomoea aquatica) and water lettuce (Pistia stratiotes) ", IOP Conf. Ser.: Earth Environ. Sci., vol. 191 , p. 012054 , nov. 2018 , doi: 10.1088/17551315/191/1/012054.

[7] P. Chiranjeevi, G. Mohanakrishna, et S. Venkata Mohan, « Rhizosphere mediated electrogenesis with the function of anode placement for harnessing bioenergy through $\mathrm{CO} 2$ sequestration ", Bioresource Technology, vol. 124, p. 364-370, nov. 2012, doi: 10.1016/j.biortech.2012.08.020.

[8] P. J. Sarma et K. Mohanty, « Epipremnum aureum and Dracaena braunii as indoor plants for enhanced bio-electricity generation in a plant microbial fuel cell with electrochemically modified carbon fiber brush anode ", Journal of Bioscience and Bioengineering, vol. 126, $\mathrm{n}^{\circ} 3$, p. 404-410, sept. 2018, doi: 10.1016/j.jbiosc.2018.03.009.

[9] M. A. Moqsud, J. Yoshitake, Q. S. Bushra, M. Hyodo, K. Omine, et D. Strik, « Compost in plant microbial fuel cell for bioelectricity generation », Waste Management, vol. 36, p. 63-69, févr. 2015, doi: 10.1016/j.wasman.2014.11.004.

[10] K. Wetser, J. Liu, C. Buisman, et D. Strik, « Plant microbial fuel cell applied in wetlands: Spatial, temporal and potential electricity generation of Spartina anglica salt marshes and Phragmites australis peat soils », Biomass and Bioenergy, vol. 83, p. 543-550, déc. 2015, doi: 10.1016/j.biombioe.2015.11.006.

[11] N. Degrenne, «Gestion de l'énergie des piles à combustible microbiennes », 2012. 
[12] K. Takanezawa, K. Nishio, S. Kato, K. Hashimoto, et K. Watanabe, « Factors Affecting Electric Output from Rice-Paddy Microbial Fuel Cells », Bioscience, Biotechnology, and Biochemistry, vol. 74, $\mathrm{n}^{\mathrm{o}}$ 6, p. 1271-1273, 2010, doi: 10.1271/bbb. 90852

[13] M. Helder, D. P. B. T. B. Strik, H. V. M. Hamelers, R. C. P. Kuijken, et C. J. N. Buisman, « New plantgrowth medium for increased power output of the Plant-Microbial Fuel Cell », Bioresource Technology, vol. 104, p. 417-423, janv. 2012, doi: 10.1016/j.biortech.2011.11.005.

[14] N. F. Tapia, C. Rojas, C. A. Bonilla, et I. T. Vargas, «A New Method for Sensing Soil Water Content in Green Roofs Using Plant Microbial Fuel Cells », Sensors, vol. 18, $\mathrm{n}^{\circ}$ 1, p. 71, janv. 2018, doi: 10.3390/s18010071.

[15] C. Xia, D. Zhang, W. Pedrycz, Y. Zhu, et Y. Guo, «Models for Microbial Fuel Cells: A critical review », Journal of Power Sources, vol. 373, p. 119-131, janv. 2018, doi: 10.1016/j.jpowsour.2017.11.001.

[16] K. Rabaey et al., "Cathodic oxygen reduction catalyzed by bacteria in microbial fuel cells », ISME
Journal, vol. 2, $\mathrm{n}^{\mathrm{o}}$ 5, p. 519-527, 2008, doi: 10.1038/ismej.2008.1.

[17] M. Helder, « Design criteria for the Plant-Microbial Fuel Cell », 2012.

[18] R. A. Timmers, D. P. B. T. B. Strik, H. V. M. Hamelers, et C. J. N. Buisman, «Electricity generation by a novel design tubular plant microbial fuel cell », Biomass and Bioenergy, vol. 51, p. 60-67, avr. 2013, doi: 10.1016/j.biombioe.2013.01.002.

[19] J.-Y. Nam, H.-W. Kim, K.-H. Lim, H.-S. Shin, et B. E. Logan, «Variation of power generation at different buffer types and conductivities in single chamber microbial fuel cells », Biosensors and Bioelectronics, vol. 25, $\mathrm{n}^{\circ}$ 5, p. 1155-1159, janv. 2010, doi: 10.1016/j.bios.2009.10.005. 